\title{
REQUERIMENTOS ECOLÓGICOS DE ESPÉCIES COM POTENCIAL PAISAGÍSTICO DA RESTINGA DE MARACANÃ, PARÁ
}

Lilian Carla Ferreira Favacho; Mário Augusto G. Jardim²; Fábio Gomes de Oliveira ${ }^{4}$

\section{RESUMO}

O potencial paisagístico pode ser atribuído a todo vegetal que apresente um uso ornamental e de maneira geral, qualquer vegetal poderá ter essa finalidade. Este trabalho teve como objetivo identificar alguns requerimentos ecológicos de espécies vegetais com potencial paisagístico da restinga da Área de Proteção Ambiental, Algodoal-Maiandeua, Maracanã, Pará, Brasil. Foram investigadas oito espécies entre árvores, palmeiras e arbustos. Observou-se que as características dominantes foram: propagação sexuada por sementes, luminosidade média e plantio indicado no ambiente externo. As espécies apresentam potencial para arborização urbana e jardins. Novas pesquisas poderão auxiliar no cultivo e na comercialização.

Palavras-chave: Espécies Nativas, Ecologia, Valoração de Recursos Naturais.

\section{REQUIREMENTS OF SPECIES WITH POTENTIAL ECOLOGICAL LANDSCAPE OF THE SAND COASTAL OF MARACANÃ, PARA}

\section{ABSTRACT}

The potential landscape can be attributed to the whole plant to submit an ornamental use and in general, any vegetable can have this purpose. This study aimed to identify some ecological requirements of plant species with the potential landscape of the sand coastal of the Environmental Protection Area, Algodoal-Maiandeua, Maracanã, Pará, Brazil. Eight species were investigated between trees, palms and shrubs. It was observed that the dominant characteristics are: propagation by seed and planting indicated average brightness in the external environment. The species have potential for urban trees and gardens. New research may help in the cultivation and marketing.

Key Words: Floristic Composition, Ecologic Status, Propagation, External and Internal Environment.

\footnotetext{
${ }^{1}$ Eng.Ftal. Mestre em Botânica Tropical. Museu Paraense Emilio Goeldi. Coordenação de Botânica, Belém-Pará:Ifavacho@museu-goeldi.br

${ }^{2}$ Pesquisador Titular. Museu Paraense Emilio Goeldi. Coordenação de Botânica, Belém-Pará:jardim@museu-goeldi.br

${ }^{3}$ Bolsista PIBIC/CNPq. Museu Paraense Emilio Goeldi. Coordenação de Botânica, Belém-Pará:fg_oliveira@yahoo.com.br

${ }^{4}$ recebido em 07.05.2013 e aceito para publicação em 15.06.2013
} 


\section{INTRODUÇÃO}

O potencial paisagístico pode ser atribuído a todo vegetal com uso ornamental em um ambiente (TOMBOLATO, 2008). Segundo Heiden et al. (2006) as civilizações primitivas já notavam as plantas que possuíam forma e estética. Com o passar do tempo o crescimento populacional suprimiu muitos espaços verdes, levando a riqueza de espécies nativas ao declínio. Em decorrência, houve um aumento na implantação do paisagismo urbano para promover a qualidade do solo, a criação de locais de recreação e a revitalização econômica de bairros.

Para conservar a biodiversidade em espaços urbanos, é importante envolver o uso de espécies nativas (ISERNHAGEM et al., 2009). Para tal, Stumpf et al. (2007) e Reis et al. (2003) sugerem que os espaços urbanos tentem resgatar a paisagem original da região também com um olhar criativo de uma nova percepção por parte dos habitantes, contribuindo na re-educação da valorização da biodiversidade no ambiente urbano.

A inserção de espécies nativas no mercado nacional pode contribuir com o desenvolvimento e ampliar a oferta de produtos e valorizar a diversidade biológica. O Brasil é um País com grande biodiversidade florística onde cerca de 5.000 espécies nativas são utilizadas na arborização urbana (VEIGA et al., 2009). No entanto, introduzir espécies nativas na cadeia produtiva requer investimento em pesquisa e treinamento para a readequação da produção (HEIDEN et al., 2006).

Para Tombolato (2008) as espécies ornamentais nativas constituem uma alternativa de renda para pequenos e médios agricultores. Apesar de haver uma demanda para utilização de espécies nativas nos projetos paisagísticos o setor produtivo ainda não está preparado, portanto, torna inviável o fortalecimento de uma proposta de paisagismo ecológico e regionalizado (HEIDEN et al., 2006)

O objetivo da pesquisa foi identificar e descrever os requerimentos ecológicos de espécies com potencial para paisagismo da restinga da Área de Proteção Ambiental, Ilha de Algodoal-Maiandeua, Maracanã, Pará, Brasil.

\section{MATERIAIS E MÉTODOS}

\section{Área de estudo}

A Área de Proteção Ambiental, Algodoal/Maiandeua está localizada no município de Maracanã, nordeste do estado do Pará, Brasil. Essa APA é uma ilha oceânica situada a $200 \mathrm{~km}$ de Belém nas coordenadas geográficas $00^{\circ} 35^{\prime}$ 03” a $00^{\circ} 38^{\prime} 29^{\prime \prime}$ de latitude sul e $47^{\circ} 31^{\prime} 54^{\prime \prime}$ a $47^{\circ} 34^{\prime}$ 57” de longitude oeste (MARGALHO et al., 2009). As espécies foram registradas com câmera fotográfica modelo Cannon. Os registros fotográficos foram enviados para a Coordenação de Botânica do Museu Paraense Emilio Goeldi para identificação botânica com a atualização das famílias pelo Sistema da APG III (2009). Para descrição do hábito de crescimento e do tipo de propagação das espécies utilizou-se a literatura botânica e ecológica especializada e do site 
http://floradobrasil.jbrj.gov.br. Os padrões de exigência de luminosidade (Alta, Média e Baixa) foram adotados para indicar as espécies para ambientes externo e interno.

\section{RESULTADOS E DISCUSSÃO}

Foram selecionadas oito espécies com potencial paisagístico. A Tabela 1 mostra a identificação botânica, o hábito de crescimento, o tipo de propagação e o tipo de luminosidade.

A propagação sexuada por meio de sementes foi dominante com exceção de Platonia insignis Mart. Dentre as oito espécies, quatro (4) crescem em condições de luminosidade média (característica de plantas de sucessão secundária), três (3) em alta luminosidade e uma (1) sob baixa luminosidade. Desta forma, todas as espécies possuem potencial para a arborização urbana. A propagação através de sementes foi um fator positivo para a comercialização, contudo, não existe atividade de coleta e de beneficiamento, mesmo que de forma artesanal para venda no mercado local.

Algumas características morfológicas e ambientais das espécies são demonstradas a seguir: $M$. flexuosa (Figura 1a) e M. armata (Figura 1b) são encontradas em terra firme e várzea, são palmeiras que podem atingir até $30 \mathrm{~m}$ de altura e suas raízes; possuem frutos comestíveis e são propagadas através de sementes e precisam de considerável quantidade de luz para crescer e atingir a maturidade sexual. $M$. armata tem formação de touceiras apresenta acúleos e por isso precisam ser isoladas do contato com os transeuntes (CLAY et al., 2000).

Essas espécies juntamente com outras arecáceas foram registradas na arborização urbana no Distrito Federal (Salman et al., 2008) e em oito praças no município de Planalto (BA) (Silva et al., 2012), principalmente por apresentarem bela arquitetura é uma opção para arborização de jardins, praças e canteiros centrais. A palmeira B. hirta (Figura 1c) tem elegância, pequeno porte das touceiras e quase ausência de espinhos nas folhas, ideal para jardins sombreados e ambientes internos e também pode ser utilizada na arborização de praças (LORENZI et al., 2010).

H.articulatus (Figura 1d), P. insignis (Figura 1e), C.columnaris (Figura 1f), P. frutescens (Figura 1g) e E. ovata (Figura 1h) são espécies que podem proporcionar bom sombreamento e portanto, com potencial para a arborização. São espécies com frutos comestíveis e indicadas para jardins particulares e até mesmo "jardins pomares” muito usados em casas de campo (RIZZINI e MORS, 1976).

Tabela 1. Espécies da restinga da Área de Proteção Ambiental, Algodoal-Maiandeua, Maracanã, Pará, Brasil com indicativo paisagístico caracterizadas por Família, Gênero, Espécie, Hábito de Crescimento (HC), Tipo de Propagação (TP): Sem-semente; Reb-rebroto e Tipo de Luminosidade (TL).

\begin{tabular}{lllll}
\hline \multicolumn{1}{c}{ Família } & \multicolumn{1}{c}{ Espécie } & HC & TP & Lum \\
\hline Apocynaceae & Hymathantus articulatus (Vahl) Woodson & Árvore & Sem & Alta \\
Arecaceae & Bactris hirta Mart. & Palmeira & Sem & Baixa \\
Arecaceae & Maurittiela armata Mart. & Palmeira & Sem & Alta \\
Arecaceae & Mauritia flexuosa L.f. & Palmeira & Sem & Média \\
Clusiaceae & Clusia columnaris Engl. & Àrvore & Sem & Média \\
Clusiaceae & Platonia insignis Mart. & Àrvore & Sem/Reb & Média \\
Lecythidaceae & Eschweilera ovata (Cambess.) Miers & Àrvore & Sem & Média \\
Sapindaceae & Pseudima frutescens (Aubl.) Radlk. & Arbusto & Sem & Alta \\
\hline
\end{tabular}




\section{CONCLUSÃO}

As espécies apresentam potencial para a

arborização urbana em ruas, praças e jardins como

também decoração de ambientes internos, porém o

seu uso é limitado pela carência de pesquisas sobre a propagação e o cultivo em ambiente urbano, bem como pela ausência de uma cadeia produtiva que envolva a produção e a comercialização das espécies.

Figura 1. Espécies da restinga registradas com potencial paisagístico na Área de Proteção, Algodoal-Maiandeua, Maracanã, Pará. 1a. Mauritia flexuosa L.f ; 1b. Maurittiela armata Mart.; 1c. Bactris hirta Mart.; 1d. Hymathanthus articulatus (Vahl) Dodson; 1e. Platonia insignis Mart.; 1f. Clusia columnaris Engl.; 1g. Pseudima frutescens (Aubl.) Radlk. E 1h. Eschweilera ovata (Cambess.) Miers.

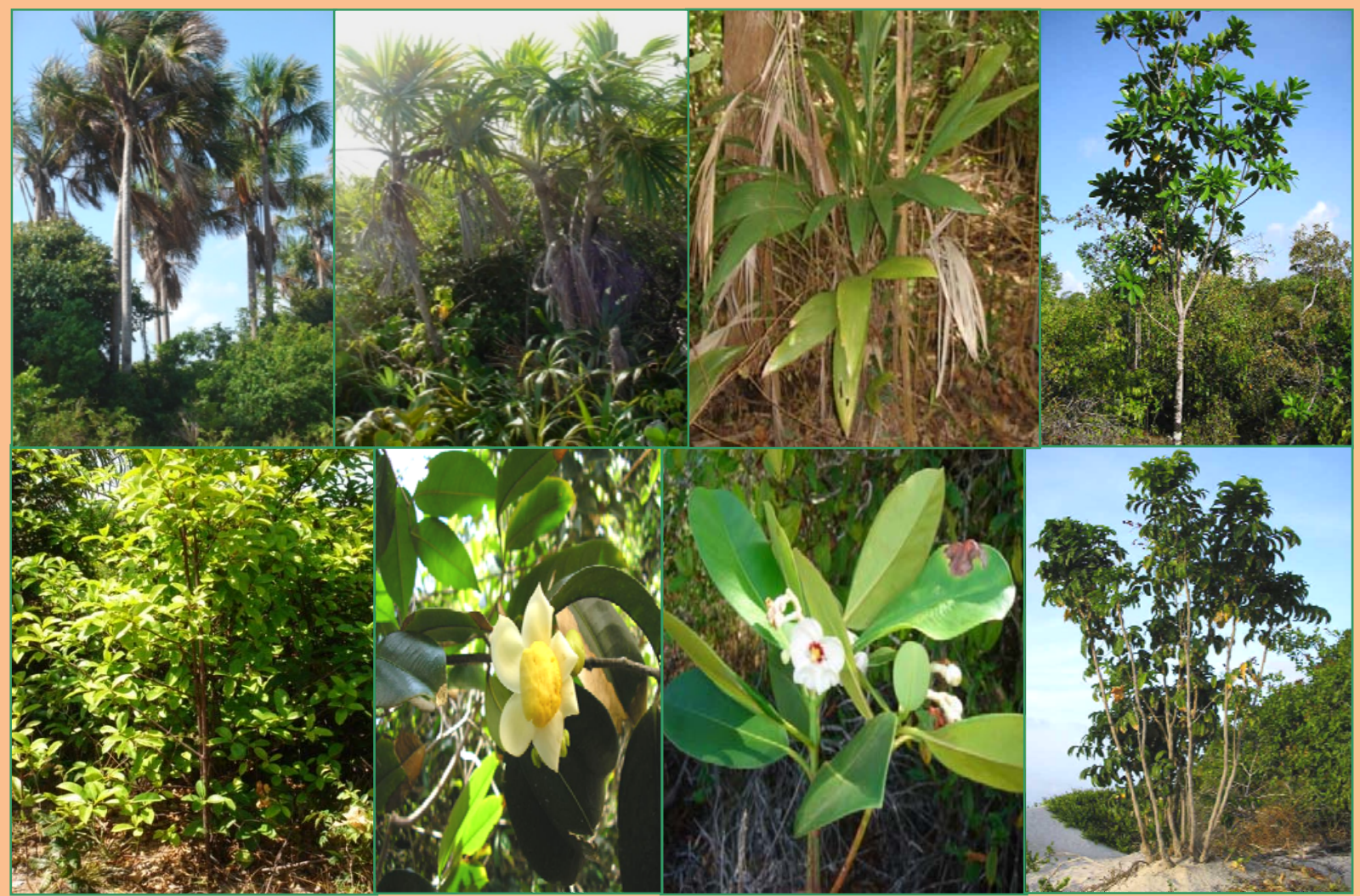

\section{REFERÊNCIAS}

THE ANGIOSPERM PHYLOGENY GROUP - APG III. An update of the Angiosperm Phylogeny Group classification for the orders and families of flowering plants: APG III. Botanical Journal of the Linnean Society, v.161, p.105-121, 2009.

CLAY, J. W.; SAMPAIO, P. T. B.; CLEMENT, C. R. Biodiversidade amazônica exemplos e estratégias de utilização. Manaus. INPA. 409p., 2000.

HEIDEN, G.; BARBIERI, R.; STUMPF, E. R. T. Considerações sobre o uso de plantas ornamentais nativas.

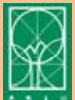

Lilian Carla Ferreira Favacho et al. 
Revista Brasileira de Horticultura Ornamental, v.12., n.1, p. 2-7, 2006.

ISERNHAGEN, I.; LE BOURLEGAT, J. M. G.; CARBONI, M. Trazendo a riqueza arbórea regional para dentro das cidades: possibilidades, limitações e benefícios. Revista da Sociedade Brasileira de Arborização Urbana, v.4., n.2, p. 26-46, 2009.

LORENZI, H.; NOBLICK, L. R.; KAHN, F.; FERREIRA, E. Flora brasileira: Arecaceae (palmeiras). Nova Odessa, São Paulo, p. 134, 2010.

MARGALHO, L. F.; ROCHA, A. E. S.; SECCO, R. S. Rubiaceae Juss da restinga da APA de Algodoal/Maiandeua, Maracanã, Pará, Brasil. Bol. Mus. Para. Emílio Goeldi, sér. Ciências Naturais, v.4., n.3, p.303-339. 2009.

REIS, A.; ANJOS, A.; BECHARA, F.C. Critérios para a seleção de espécies na arborização urbana ecológica. Sellowia, v.53., n.55, p. 51-67, 2003.

RIZZINI, C. T.; MORS, W.B. Botânica econômica brasileira. São Paulo EPU, 207p., 1976.

SALMAN, A.K.D.; LÓPEZ, G.F.Z.; BENTES-GAMA, M.M.; ANDRADE, C.M.S. Espécies arbóreas nativas da Amazônia Ocidental Brasileira com potencial para arborização de pastagens. Embrapa, documentos, 127, 20p., 2008.

SILVA, A.R.; PAULA, R.C.A.L.; PAULA, A.; FREITAS, L.C. Avaliação de espécies da arborização em oito praças do município de Planalto-BA. Enciclopédia Biosfera, v.8, n.14, p.1042-1049, 2012.

STUMPF, E. T.; HEIDEN G.; BARBIERI R. L.; FISCHER, S. Z.; NEITZKE, R. S.; ZANCHET, B.; GROLLI, P. R. Método para avaliação da potencialidade ornamental de flores e folhagens de corte nativas e não convencionais Revista Brasileira de Horticultura Ornamental, v.13, n.2, p. 143-148, 2007.

TOMBOLATO, A. F. C. Potencial ornamental de espécies nativas. Revista Brasileira de Horticultura Ornamental, v.14, n.1, p. 27-28, 2008.

VEIGA, R. F. A.; TOMBOLATO, A. F.C.; COSTA, A. A.; BARBOSA, W. Levantamento de plantas ornamentais nativas, mantidas sob conservação ex situ no Brasil. Revista Brasileira de Horticultura Ornamental, v.15, n.1, p.11- 22, 2009. 